\title{
(2) OPEN ACCESS \\ Cerebral air embolism after indwelling pleural catheter insertion in a chronic hydropneumothorax secondary to epithelioid mesothelioma
}

\author{
Dissanayake Mudiyanselage Chanaka Jayawardena (10 , Rakesh K Panchal, \\ Sanjay Agrawal, Indrajeet Das
}

Respiratory Medicine, Glenfield Hospital, Leicester, UK

\section{Correspondence to}

Dr Dissanayake Mudiyanselage Chanaka Jayawardena; Chanj858@gmail.com

Accepted 13 July 2021
Check for updates

(c) BMJ Publishing Group Limited 2021. Re-use permitted under CC BY-NC. No commercial re-use. See rights and permissions. Published by BMJ.

To cite: Jayawardena DMC, Panchal RK, Agrawal S, et al. BMJ Case Rep

2021;14:e244006.

doi:10.1136/bcr-2021-

244006

\section{SUMMARY}

A 75-year-old man with a history of epithelioid mesothelioma and a right-sided indwelling pleural catheter (IPC) presented with a history of a purulent fluid drainage via the IPC. The pleural fluid cultured Klebsiella oxytoca and Enterococcus faecalis. He was treated with a course of oral fluoroquinolone followed by uneventful IPC replacement. One and half hours postprocedure, the patient had a witnessed drop in conscious level accompanied by seizure like activity. Acute stroke was suspected and a CT head was performed. CT head revealed multiple serpiginous pockets of air along the cerebral fissure, with features that were highly suggestive of cerebral air embolism and multiple wedge-shaped areas of infarction involving the cerebral hemispheres. Further imaging revealed satisfactory position of the replaced IPC. The patient was admitted to the intensive care unit for high flow oxygen therapy and head down ventilation. However, his condition deteriorated and he died later.

\section{BACKGROUND}

Indwelling pleural catheters (IPC) are used in the management of benign and malignant pleural effusions. The procedure is usually carried out as a day case under local anaesthesia. IPC insertion may be associated with complications such as pleural infection, bleeding, pneumothorax, chest pain, blockage and leakage but the procedure may be associated with more serious complications.

Cerebral air embolism (CAE) is a rare but important complication of pleural procedures that has not been previously reported after IPC insertion. CAE is induced by barotrauma, chest injuries and iatrogenic causes such as cardiovascular surgery and invasive procedures. Pleural procedures such as pleural fluid aspiration, chest drain insertion and thoracoscopy have also been recognised as causes of CAE.

We report a case of CAE that occurred after the routine exchange of an IPC in a patient with a chronic complex hydropneumothorax secondary to epithelioid malignant mesothelioma

\section{CASE PRESENTATION}

A 75-year-old man with a 7-year history of epithelioid mesothelioma and a right sided IPC presented to the pleural clinic with a history of 2-3 weeks of a malodourous, purulent fluid drainage via the IPC.
The patient was Eastern Cooperative Oncology Group performance status 0 and was under the ambulatory pleural service but managed his pleural collections independently in the community. The IPC had been inserted $3 \frac{1}{2}$ years ago for a rightsided loculated hydropneumothorax that had developed after a radical extended pleurectomy, decortication and diaphragmatic patch surgery for mesothelioma. The rationale for the IPC was recurrent effusions and associated infections requiring repeat chest drains in the area of the postoperative hydropneumothorax.

The patient was asymptomatic and apyrexial. The pleural fluid cultured Klebsiella oxytoca and Enterococcus faecalis. He was treated with the oral fluoroquinolone, ciprofloxacin and given advice and guidance on infection prevention strategies when handling the IPC and pleural drainage apparatus. A couple of weeks later it was decided to replace the IPC as an elective procedure due to the long duration of the IPC, a persistent low-grade purulent discharge, concerns about bacterial colonisation and history of a similar infection episode a year ago.

On the day of the procedure, the patient reported that the IPC had partially migrated out of the pleural cavity and the tunnelled subcutaneous tract due to loss of integrity of the IPC cuff and thus came out easily without any intervention. The IPC tip was sent for culture.

On clinical examination, blood pressure was $133 / 77 \mathrm{~mm} \mathrm{Hg}$, pulse rate was 77 beats per minute, respiratory rate was 18 breaths/min and the body temperature was $36.6^{\circ} \mathrm{C}$ with oxygen saturation $98 \%$ on room air. Lung auscultation revealed inspiratory crackles at the right lower lung zone. The laboratory test revealed white cell count (WCC) count $11.3 \times 10^{9} / \mathrm{L}$, haemoglobin $108 \mathrm{~g} / \mathrm{L}$, platelets $430 \times 10^{\wedge} 9 / \mathrm{L}$ and $C$ reactive protein $71 \mathrm{mg} / \mathrm{L}$. Bedside thoracic ultrasound scan was consistent with a hydropneumothorax.

The same day the patient underwent an uneventful IPC insertion under local anaesthesia and mild sedation with $1 \mathrm{mg}$ of intravenous midazolam. Satisfactory IPC placement was confirmed on a post procedure chest radiograph (figure 1).

One and half hours postprocedure, the patient had a witnessed sudden drop in conscious level with associated seizure like activity. The patient was immediately assessed by the cardiac arrest team where blood pressure, heart rate and oxygen 


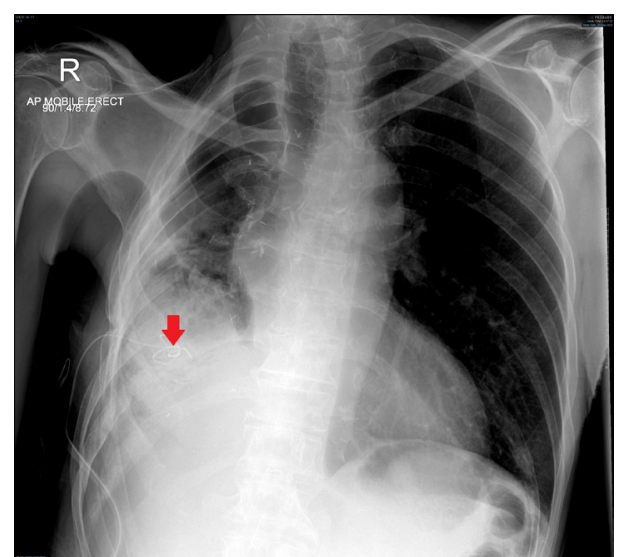

Figure 1 Postprocedure chest radiograph showing satisfactory IPC placement in chronic right hydropneumothorax (marked by red arrow). IPC, indwelling pleural catheter.

saturations were maintained within the reference range throughout. Glasgow Coma Scale (GCS) was 4 (eyes opening 1 , verbal response 1 and motor response 2). General examination did not demonstrate any peripheral stigmata of systemic air embolism and no retinal air bubbles were seen in funduscopic examination. An acute stroke was suspected and an urgent CT head was performed. Repeat blood tests revealed WCC $9.4 \times 10^{9} / \mathrm{L}$, haemoglobin $107 \mathrm{~g} / \mathrm{L}$, platelet $408 \times 10^{\wedge} 9 / \mathrm{L}$, blood urea $4.0 \mathrm{mmol} / \mathrm{L}$, serum creatinine $73 \mathrm{umol} / \mathrm{L}$, estimated glomerular filtration rate $>90, \mathrm{C}$ reactive protein $70 \mathrm{mg} / \mathrm{L}$, alanine transaminase $9 \mathrm{iu} / \mathrm{L}$. ECG was in sinus rhythm and no ischaemic changes were noted. CT head revealed multiple serpiginous pockets of air along the cerebral fissure, with features that were highly suggestive of an embolism and multiple wedge-shaped areas of infarction involving the cerebral hemispheres (figure 2). CT chest revealed satisfactory positioning of the IPC with no aetiology for the acute deterioration (figure 3). The patient was admitted to the intensive care unit for high flow oxygen therapy and head down ventilation.

\section{OUTCOME AND FOLLOW-UP}

Our patient's condition slowly deteriorated and his GCS was not improved. Following a discussion with the multidisciplinary team and family, a previous decision to manage him conservatively in

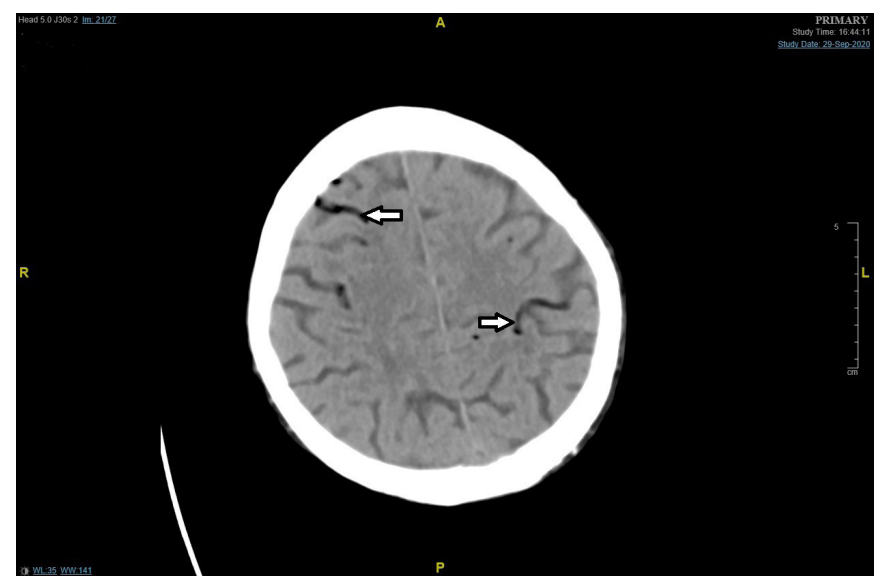

Figure 2 CT head showing multiple serpiginous pockets of air along the cerebral fissure (white arrows) suggestive of air embolism.

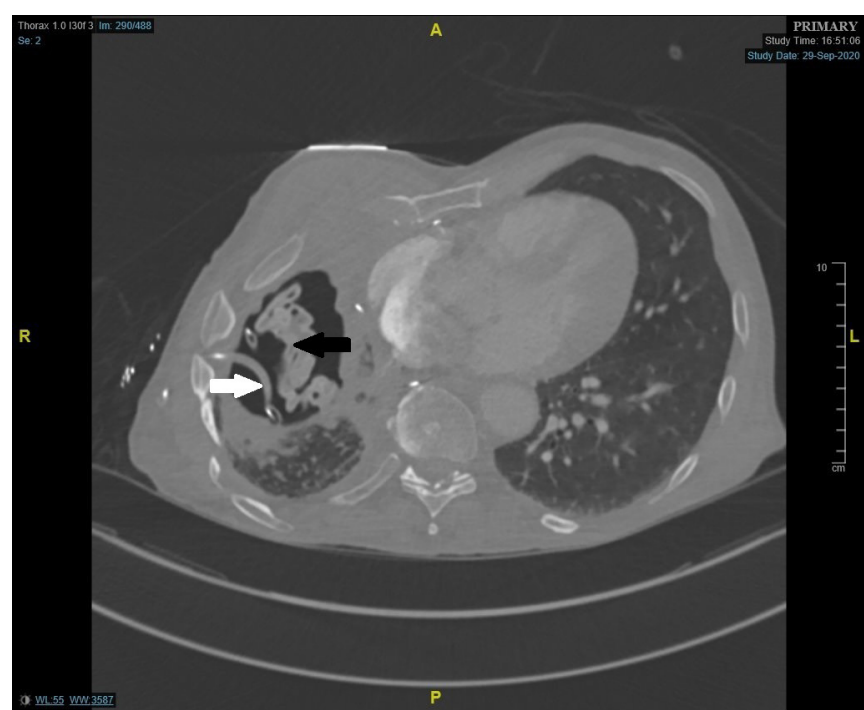

Figure 3 CT chest showing satisfactory placement of IPC (white arrow) and old diaphragmatic construction (black arrow). IPC, indwelling pleural catheter.

the event of any deterioration was respected and he was palliated. The patient died 6 days later.

\section{DISCUSSION}

Air embolism is defined as entry of air into the arterial or venous system. It may result from invasive procedures, trauma and barotrauma to the lungs. ${ }^{1}$ Arterial air has direct access to the cerebral circulation and venous air is thought to be shunted through a patent foramen ovale (PFO). In the absence of a PFO, systemic venous air needs to traverse the pulmonary vasculature. Pulmonary arterioles and capillaries act as a physical barrier for various substances entering in to the arterial circulation, but some particles can still get through pulmonary capillary filter. ${ }^{2}$ CAE of venous origin has occurred in the absence of intracardiac septal defects. ${ }^{3}$ Air directly entering into pulmonary veins, which drain into the left atrium can result in CAE without any of the mechanisms described above.

Pleural procedures can result in lung puncture and introduce gas bubbles into a pulmonary vein. Air bubbles can flow in when a needle tip enters a pulmonary vein while its base is opened to the atmosphere. The atmospheric pressure exceeds the pulmonary venous pressure during inspiration and air gets sucked into the pulmonary venous system. It may also occur when a needle penetrates both an air-containing space and a nearby pulmonary vein, causing a broncho-venous fistula. Coughing or a Valsalva manoeuvre may increase airway pressure and air enters the pulmonary vein. ${ }^{45}$

One cannot be sure of the exact incidence of iatrogenic air embolism but it has been reported to be as low as 2.65/100 000 and is therefore not routinely consented for at the time of pleural procedures. ${ }^{6}$ The fatality rate in CAE has been reported to be as high as $21 \%$ although there are very few case reports of CAE in the literature. ${ }^{7}$ Knowledge of CAE is important for patients and operators given the large volume of commonly performed thoracic procedures in which CAE could occur such as percutaneous transthoracic needle lung biopsy, thoracentesis, chest drain insertion, intrapleural fibrinolytic therapy and pleural lavage. ${ }^{1}$ CAE occurring after IPC insertion has not been reported.

At 7 years postdiagnosis, our patient had defied the odds in terms of his survival from mesothelioma. Mean 1-year survival 
rate for mesothelioma in men aged above 75 years in UK is $29.8 \%$ and 5 -year survival rate for the same group is $3 \%{ }^{8}$ Our patient's performance status was zero, despite his chronically distorted intra-thoracic anatomy due to previous mesothelioma surgery, a dehisced diaphragmatic patch and a loculated pneumothorax.The cause of CAE in our patient is not clear as there were no immediate complications at the time of the IPC procedure and subsequent radiology confirmed satisfactory position of the IPC with no trauma to the lung or any major blood vessels but it is likely that he had a pulmonary venous air embolism.

We hypothesise that the chronic anatomical and associated pathological changes may have resulted in inflammatory and friable intrathoracic tissue and (1) development of a breach or fistulae in a part of the collapsed lung and/or an adjacent vessel or (2) development of an arteriovenous malformation, either of which may have been aggravated by the replacement IPC and on Valsalva due to coughing lead to pressure changes and ingress of air into a branch pulmonary vein and subsequent embolisation with the catastrophe that ensued.

CAE is often a retrospective clinical diagnosis, based on a high suspicion of a patient having sudden onset and unexplained neurological symptoms following an invasive procedure as in our case. CT brain in the acute phase can demonstrate air bubbles in the cerebral arteries. In addition careful fundoscopic examination can reveal air bubbles in the retinal vasculature. ${ }^{49}$

If CAE is suspected treatment should not be delayed while the diagnosis is established. Therapeutic measures includes administration of high-flow oxygen to reverse the cerebral ischaemia and placing the patient in a lateral decubitus position with head down or Trendelenburg position in order to facilitate retrograde flow of air bubbles from the cerebral arteries. ${ }^{10}$

Hyperbaric oxygen therapy (HBOT) is the most effective treatment for CAE and reduces the size of the air bubbles causing obstruction to the cerebral circulation. HBOT also increases the soluble oxygen availability for ischaemic tissues. According to Boyle's law,by increasing the pressure we can compress the size of air bubbles to release the obstruction and establish perfusion. Giving HBOT is also thought to reduce cerebral oedema by decreasing the permeability of the blood-brain barrier. ${ }^{9}$ Unmanaged pneumothorax is an absolute contraindication for HBOT but otherwise it is a simple and safe procedure,although not always readily available. ${ }^{11}$

Early detection and thereafter prompt management is essential to reduce morbidity and mortality. In one series of 16 patients treated with hyperbaric oxygen, $50 \%$ patients had complete recovery, 31\% had partial relief and $19 \%$ had no benefit with death in $12.5 \%$ patients. ${ }^{12}$ In our case, the patient was given $100 \%$ oxygen therapy and not considered for mechanical ventilation or HBOT given his poor physiological reserve due to mesothelioma and the hydropneumothorax.

In conclusion, iatrogenic CAE is extremely rare in pleural interventions but it carries significant mortality and morbidity. A high degree of clinical suspicion is needed to diagnose CAE suggested by unexplained neurological symptoms following an invasive procedure. Prompt treatment of CAE is required. Giving 100\% high flow oxygen therapy will increase the tissue oxygenation and reduce burden of air emboli by eliminating nitrogen. HBOT is the most effective treatment of CAE, but contraindication in unmanaged pneumothorax and accessibility may limit utilisation of HBOT. As pleural procedures are widely carried out in outpatient and inpatient settings, clinicians need to be competent in diagnosing and managing CAE.
Learning points

- Cerebral air embolism is a rare but important complication of pleural procedures, which carries significant mortality and morbidity.

- Diagnosis is based on a high degree of suspicion in a patient developing unexplained neurological symptoms following an invasive procedure.

- Administering high-flow oxygen and hyperbaric oxygen therapy with management in the Trendelenburg position is the main mode of treatment.

- Early detection and prompt treatment can reduce the morbidity and mortality.

Twitter Dissanayake Mudiyanselage Chanaka Jayawardena @chanaka jayawardena Acknowledgements Ms S.Johnstone (Pleural Specialist nurse), Gelnfield Hospital. Dr A. Deshpande (Consultant Radiologist), Glenfield Hospital. Dr S. Harieaswar (Consultant Radiologist), Glenfield Hospital.

Contributors DMCJ Managed the patient and drafted the manuscript, RKP managed the patient as the leading respiratory consultant, supervised, reviewed and edited the manuscript. SA manged the patient as ITU consultant, reviewed and edited the manuscript. ID reviewed and edited images and provided radiological opinion

Funding The authors have not declared a specific grant for this research from any funding agency in the public, commercial or not-for-profit sectors.

Competing interests None declared.

Patient consent for publication Next of kin consent obtained.

Provenance and peer review Not commissioned; externally peer reviewed.

Open access This is an open access article distributed in accordance with the Creative Commons Attribution Non Commercial (CC BY-NC 4.0) license, which permits others to distribute, remix, adapt, build upon this work non-commercially, and license their derivative works on different terms, provided the original work is properly cited and the use is non-commercial. See: http://creativecommons.org/ licenses/by-nc/4.0/.

\section{ORCID iD}

Dissanayake Mudiyanselage Chanaka Jayawardena http://orcid.org/0000-00021326-5441

\section{REFERENCES}

1 Kim SI, Kwak HJ, Moon J-Y, et al. Cerebral air embolism following pigtail catheter insertion for pleural fluid drainage. Tuberc Respir Dis 2013;74:286-90.

2 Heinemann HO, Fishman AP. Nonrespiratory functions of mammalian lung. Physiol Rev 1969;49:1-47

3 Marquez J, Sladen A, Gendell H, et al. Paradoxical cerebral air embolism without an intracardiac septal defect. J Neurosurg 1981;55:997-1000.

4 Um SJ, Lee SK, Yang DK, et al. Four cases of a cerebral air embolism complicating a percutaneous transthoracic needle biopsy. Korean J Radiol 2009;10:81-4.

5 Westcott JL. Air embolism complicating percutaneous needle biopsy of the lung. Chest 1973:63:108-10.

6 Beevor H, Frawley G. latrogenic cerebral gas embolism: analysis of the presentation, management and outcomes of patients referred to the Alfred Hospital hyperbaric unit. Diving Hyperb Med 2016;46:15-21.

7 Gou X-H, Yang W, Zhang Y-L, et al. A case of massive cerebral arterial air embolism induced by artificial pneumothorax and its analysis. Med Princ Pract 2019:28:297-300.

8 Office for National Statistics. Cancer survival in England: adults diagnosed in between 2013 and 2017 and followed up to 2018, 2021. Available: https://www.ons.gov.uk/ peoplepopulationandcommunity/healthandsocialcare/conditionsanddiseases/datasets/ cancersurvivalratescancersurvivalinenglandadultsdiagnosed [Accessed 24 Apr 2021].

9 Muth CM, Shank ES. Gas embolism. N Engl J Med 2000:342:476-82.

10 Hare SS, Gupta A, Goncalves ATC, et al. Systemic arterial air embolism after percutaneous lung biopsy. Clin Radiol 2011;66:589-96.

11 Capron T, Guinde J, Laroumagne S, et al. Cerebral air embolism after pleural lavage for empyema. Ann Thorac Surg 2020:110:e289-91.

12 Murphy BP, Harford FJ, Cramer FS. Cerebral air embolism resulting from invasive medical procedures treatment with hyperbaric oxygen. Ann Surg 1985;201:242-5. 
Copyright 2021 BMJ Publishing Group. All rights reserved. For permission to reuse any of this content visit https://www.bmj.com/company/products-services/rights-and-licensing/permissions/

BMJ Case Report Fellows may re-use this article for personal use and teaching without any further permission.

Become a Fellow of BMJ Case Reports today and you can:

- Submit as many cases as you like

- Enjoy fast sympathetic peer review and rapid publication of accepted articles

Access all the published articles

- Re-use any of the published material for personal use and teaching without further permission

Customer Service

If you have any further queries about your subscription, please contact our customer services team on +44 (0) 2071111105 or via email at support@bmj.com.

Visit casereports.bmj.com for more articles like this and to become a Fellow 